\title{
Formation of Effective Investment Portfolios on the Financial Markets: Estimation and Management Models
}

\author{
Yulia Eduardovna Slepukhina \\ Doctor of economics, professor, Graduate School of Economics and Management, \\ Ural Federal University, 19 Mira St., 620002 Ekaterinburg, Russia \\ Julya.Slepuhina@yandex.ru \\ Alexandr Yurievich Kazak \\ Doctor of economics, professor, Graduate School of Economics and Management, \\ Ural Federal University, 19 Mira St., 620002 Ekaterinburg, Russia \\ akazak@k66.ru
}

\section{Doi:10.5901/mjss.2015.v6n2s4p21}

\begin{abstract}
The articles deal with consideration of actual issues of formation of effective investment portfolios on the financial markets, in particular, the portfolio of such active institutional investors, as insurance company. The necessity of effectiveness enhancement of investment activity of insurance institutes in the modern conditions was substantiated; the model of insurer's investment portfolio management, within which the non-linear multi-criteria management task is solved, where criteria include profit maximization and portfolio risk minimization, was developed. The solution of this task, based upon methodological application of theory of non-antagonistic positional differential games.
\end{abstract}

Keywords: investment portfolio, financial markets, profitability, bimatrix game, Nash equilibrium.

\section{Introduction}

The stable development of world economy is in many respects determined by the state of market infrastructure, that is impossible without reliable system of insurance, and one of the main and decisive factors of stability of insurance market are effectiveness of the investment activity of its participants - insurance companies (Slepukhina, 2006). At that on the one part, the effective management of investment portfolio of insurer promotes to increase of profitability, solvency and financial stability of concrete insurance organizations (on microlevel), and on the other part, the investment function of insurance category is implemented by means of active investment activity of insurance and reinsurance companies, namely, through investments of temporarily free monetary flows of insurance reserves (and own funds) into different assets and stock exchange instruments and other markets, the financing of economy on the whole (on macrolevel) takes place (Slepukhina, 2013).

In the conditions of overcoming of negative consequences of world crisis phenomena and implementation of geopolitical risks the problem of investment activity effectiveness enhancement of the insurance companies and improvement of the system of management of investment potential of insurance market, on the whole, requires the special actuality.

It should be noted that effectiveness of investment activity of Russian insurers since the beginning of demonopolization of the insurance market is traditionally considered to be very low, although their investment potential (especially, in the aspect of "long" moneys) in many respects exceeds the potential of other institutional investors (Slepukhina, 2011). Although this problem was considered by some Russian scientists (as a rule, by insurerspractitioners), but is enough undeveloped, including because in the conditions of execution of all requirements of state regulator of the insurance market on allocation of temporarily free monetary flows (insurance reserves and own fund) in the insurer, there almost doesn't remain possibility of maneuvers on formation of effective investment portfolio from the point of view of optimal combination of profitability and risk (Kazak \& Slepukhina, 2013). 


\section{Methods}

In our opinion, the reasons of low investment activity of Russian insurers, and as a result of low effectiveness of their investment activity are connected with:

- on the one part, with imperfection of the active legislation in the area of insurance, as in the conditions of execution of requirements on investment and observance of structural correlations of assets, taken as a coverage of insurance reserves, the insurers almost have no possibility of risk hedging with assistance of derivative financial instruments, and correspondingly, portfolio formation with higher profitability (about insurance business organization in the Russian Federation. The Federal Law from $27^{\text {th }}$ of November in 1992 under No. 4015-1 in the version of Federal Law from 10.12.2003 under No. 172-FL; the Decree of MF of RF from 02.07.2012 under No. 100n "On approval of allocation rules of insurance reserve resources by the insurers");

- on the other part - with unpreparedness of insurers to use instruments of stock exchange and other markets, financial engineering products available and successfully applied in the world practice, and adapt the existing methods of management of investment portfolio to the specificity of insurance companies.

The participation of the insurer in the investment activity makes essential effect both on the sources and volume of insurance reserves, and on their content. Firstly, the successful investment activity gives possibility to insurance organization to use the part of profit from it for covering of the negative financial result of insurance operations, which can be result of both increased non-profitableness of this year, and the highest competition on the insurance market.

Secondly, the participation in the investment activity will give the insurer a possibility to transmit the part of profit to the insurer. As a rule, the obligations of such kind are provided at contract conclusion. With the purpose of fund accrual for payment to insurer, the special reserves (funds) are formed.

Thirdly, the investment profit is the source of own capital growth, which in force-majeure circumstances can be used for covering insurance obligations, being for insurance organization as specific fund of self-insurance (Slepukhina, 2010a).

The sources of investments of insurance company are own funds and attracted resources, among which the insurers' funds, materialized in the form of insurance reserves, are the sources of insurance company investments (Slepukhina, 2010b).

\section{Results and Discussion}

The possibility of investing of the collected premiums on the financial market contributes the certain specificity in the calculation of risks and have considerable effect on the values of own funds (Slepukhina, 2013). Let's show it on the following example.

May the financial market be specified $((B, S)$ - market), consisting of two assets: $B$ (riskless) and $S$ (risk), which prices evolve in accordance with different equations:

$$
\Delta B_{n}=r B_{n-1}, B_{0}>0 \text {, }
$$

$\Delta S=\rho_{n} S_{n-1}, S_{0}>0, n \leq N$

where $\left\{\rho_{n}\right\}_{n \leq N}$ is the sequence of independent and equally distributed random values, which take two meanings $b$ and $a$ with probabilities $p$ and $q=1-p$ respectively, at that $-1<a<2<b$.

The insurance company that forms its capital in the following way works on this market: at the primary point of time $n=0$, having the capital $R$, the company invests it on $(B, S)$ market, distributing it between two available assets. The pair $\left(\beta_{1}, \gamma_{1}\right)$ will mark the quantity of assets $B$ and $S$ respectively, i.e.

$$
R_{0}=\beta_{1} \cdot B_{0}+\gamma_{1} \cdot S_{0},
$$

In the point of time $n=1$ the prices for assets of $(B, S)$ market change, the company receives the insurance fees $C$ and make payments $Z i$, where $Z i$ is positive random value. The capital in the point of time $n=1$ is equal to

$R_{1}=\beta_{1} B_{1}+\gamma_{1} S_{1}+c-Z_{1}$,

The company again distributes this capital on $(B, S)$ market and forms the pair $\left.{ }^{(} \beta_{2}, \gamma\right)$, as

$R_{1}=\beta_{2} \cdot B_{1}+\gamma_{2} \cdot S_{1}$,

In the point of time $n=2$ the price for assets of $(B, S)$ market changes, the company receives the insurance fees $c$ and make payments $Z_{2}$, where $Z_{2}$ positive random value etc. In the point of time $n$ the capital of company has the view:

$$
R_{n}=\beta_{n} B_{n}+\gamma_{n} S_{n}+c-Z_{n},
$$


The sequence $\pi=\left\{\beta_{n}, \lambda_{n}\right\}_{n>0}$ as a rule is interpreted as strategy, or company portfolio, at that the pair $\left(\beta_{m}, \gamma_{m}\right)$ is chosen on the basis of information about evolution of prices for $B$ and $S$ assets in the point of time $k=0,1, \ldots, n-1$.

As it was marked above, the task about study of company solvency is typical for insurance risk theory. Determining bankruptcy of the company as the event for this situation $\left\{w: R_{n}<0\right.$ for some $\left.n>0\right\}$, the task of solvency can be also interpreted as the task about its non-bankruptcy (or bankruptcy).

The study of solvency should be conducted, as a matter of fact, for big number of "steps" of the company activity (Slepukhina, 2011). The basic supposition lies in that the values of customers' claims to the company $\left(Z Z_{j}=1,2, \ldots\right.$ are independently equal distributed positive random values, which don't depend on the evolution of assets of $(B, S)$ market. The function of distribution $\mathrm{Zi}$ will be marked as $F_{Z i}, F_{Z i}=F z$.

Taking into account the obtained equations the dynamics of capital of insurance company is described with equation:

$$
R_{n+1}=\beta_{n} B_{n+1}+\gamma_{n} S_{n+1}+c-Z_{n+1}=R_{n}(1+r)+\gamma_{n} S_{n}\left(\rho_{n+1}-r\right)+c-Z_{n+1}
$$

May at first all capital after payments on obligation be invested in riskless asset, and consequently,

$$
R_{n+1}=R_{n}(1+r)+c-Z_{n+1}
$$

If in $k$ point of time the amount to payment exceeded the capital, accrued to this time, the bankruptcy is fixed on $k$ step, and company ceases its activity.

Let's consider the case of investment in both assets on $(B, S)$ market.

$$
\text { In this case } \alpha_{n}=\frac{\gamma_{n+1} S_{n}}{R_{n}} \text { is }
$$

of risk asset and exponential distribution of payments it is possible to receive the upper evaluation of probability function

of non-bankruptcy. As $\gamma_{n+1}$ is the quantity of asset $S$, which the company acquires in the point $n$ after obtainment of premium $c$ and payments $Z_{n}$, having as a result the capital $R_{n}$, them this is the share of assets in the portfolio.

Thus, at the conditions of investment of funds in the earning assets, taking into account the probability of financial losses, the basic condition of non-bankruptcy of insurance company is the condition of capital sufficiency (own funds).

In practice, the solution of task for optimal management of financial asset portfolio is traditionally based on the methods of qualitative analysis of market prices. The prophecy of direction of asset cost and development of market strategy for decrease of financial loss risk seem to be the most important practical task of technical analysis of financial investment of the insurer (Slepukhina, 2010c).

It should be emphasized that his method, first of all, has the great extent of uncertainty in the respect that as a result of its application the concrete recommendations are not developed in relation to how, having the primary state of assets and liabilities structure, to transit to the best state from the point of view of optimal combination of two management aims: profit maximization and risk minimization, and secondly, doesn't consider the investment insurer's portfolio, which consist of several assets (in practice, undoubtedly, more than two). In order to have possibility to take decisions on the basis of dynamic interaction of these criteria, it is necessary to set and study the multi-criteria task of investment portfolio management within the framework (Slepukhina \& Kleimenov, 1998).

In the model, developed by the author and represented below, the setting of the non-linear multi-criteria management task is suggested, where the criteria include profit maximization and risk minimization at provision of the necessary level of liquidity, repayment, profitability, diversification, and also observance of the structural correlation of assets, accepted as the coverage for insurance reserves (in accordance with the decree of MF of RF from 02.07.2012 under No. 100n). The solution of this task, based upon application of methods of non-antagonistic positional theory of differential games, is represented.

\subsection{Economic-mathematical model of insurer's investment portfolio management}

The investments of insurance organization within the framework of model are characterized by the following set of indicators:

$C P$ - the value of insurance reserves, which determines the cost of portfolio, consisting of $N$ assets (including, if only the funds of insurance reserves are invested); in the total case the cost of portfolio $P=C P+C C$, as also the own funds (CC) can be invested.

$A i$ - the cost of $i$ asset, taken as coverage for insurance reserves.

$\mathrm{Ui}$ - the specific weight of $i$ asset in the cost of portfolio, $\mathrm{Ui}=\mathrm{Ai} / \mathrm{P}$

The expected profitability of $i$ asset $\left(P_{p^{\prime}}\right)$. 
The expected risk of $i$ asset, expressed by the standard deviation - $\left(r_{i}\right)$. As a matter of fact, the risk indicator represents deviation from the actual profitability asset from the expected one, at that the deviations in lesser or bigger direction are taken into account, but when we speak about risk minimization, we certainly mean the probability of appearance of negative financial result, i.e., when the actual asset profitability, taken as coverage of insurance reserves turned out to be expected one. portfolio:

Then the profitability of portfolio will be determined as average-weighed amount of profits included in the asset

$$
E(r)=\sum_{i=1}^{n} U_{i} \cdot P_{p}^{i}
$$

The expected risk of portfolio will be represented as:

$$
R=\sum_{i=1}^{n} \sum_{j=1}^{n} U_{i} \cdot U_{j} \cdot \operatorname{Cov}_{i j}
$$

where $\operatorname{Cov}_{i j}=\frac{\sum_{k=1}^{n}\left(p i_{k}-\overline{p i}\right)\left(p j_{k}-\overline{p j}\right)}{n-1}$ - covariation of $i$ and $j$ assets, pik, pjk - asset profitability $i$ and $j$ in q-tive case, $n$ - the number of cases of asset profitability registration.

The requirements, imposed on the maximal volume of assets by the structural correlations of assets, taken as the coverage of insurance reserves (in accordance with the degree No. 100n), will be recorded in the form of limitations:

$$
U i \cdot C P \leq c_{i}
$$

Within the frameworks of the developed model, we'll restrict ourselves with the consideration of portfolio, made from 5 following assets (as the analysis of insurer's investment portfolio showed, namely these assets are the most popular at coverage of insurance reserves), in the general case of a portfolio that consists of $\mathrm{N}$ assets, the task is solved similarly. Thus, let's suggest that the insurance reserves are located in the following instruments of stock exchange market:

1) deposits in banks, including those ones, which were attested as deposit certificates; the specific weight in portfolio $U 1$, expected profitability $P_{p}{ }^{1}$;

2) the state securities; specific weight in portfolio $U 2$, expected profitability $P_{p}^{2}$;

3) bank bills of exchange; specific weight in portfolio $U 3$, expected profitability $P_{p}^{3}$;

4) corporate securities - shares; specific weight in portfolio U4, expected profitability $P_{p}^{4}$;

5) corporate bonds; specific weigh in portfolio (1 - U1 - U2 - U3 - U4), specific profitability $P_{p}^{5}$.

\subsection{Statistic task}

Components of management in the present task $-u 1, u 2, u 3, u 4$.

The function of profitability (1) will be marked as $F 1(u 1, u 2, u 3, u 4)$, and it is more comfortable to use the function of risk (2) is with the opposite sign:

F2(u1, u2, u3, u4)=-R(u1, u2, u3, u4)

Conditions (2) actually give the area of determination of functions $F 1(u 1, u 2, u 3, u 4)$ and $F 2(u 1, u 2, u 3, u 4)$. This area represents the Deckart's work in the plain multitude $P(u 1, u 2)$ and $S(u 3, u 4)$, from which the conditions (3) "cut" the multitude $M$ in 4-dimensional space.

Thus, we come to the following combined task:

$$
\left\{\begin{array}{c}
F_{1}\left(u_{1}, u_{2}, u_{3}, u_{4}\right) \rightarrow \max \\
F_{2}\left(u_{1}, u_{2}, u_{3}, u_{4}\right) \rightarrow \max \\
\left(u_{1}, u_{2}, u_{3}, u_{4}\right) \in M
\end{array}\right.
$$

The task (4) represents non-linear statistic multi-criteria task. The non-linearity of the task is conditioned firstly, by non-linearity of function $F_{2}$, and secondly, by non-linearity of limitations.

\subsection{The dynamic task}

The time $t$ can be considered as discretely changeable value, i.e.:

$t=1,2,3, \ldots$ (1 month, 2 months, ...)

Then the dynamic task is formed from the sequence of statistic tasks (4), at that it is important that multitude $\mathrm{M}$ depends on the parameter values, set on each step.

The method of statistic and dynamic task. Usually as a solution of statistic multi-criteria task the pareto elements 
are taken (elements according to Pareto) of $M$ multitude (in relation of $F_{1}, F_{2}$ indicators). However, there is the whole number of pareto elements, as a rule, and the problem of choice of the single elements from this multitude appear.

In this work as solution of the statistic multi-criteria task, the decision based upon approach that uses the idea of theory of positional differential games. The essence of approach in non-antagonistic games firstly lies in that along the trajectory, generated by the solution, the functions of ensured result of each player must steadily increase (not decrease) and, secondly, the choice of player's managements in each current point of time is executed on the basis of Nash solutions (solutions according to Nash) of some additional bimatrix game. In the repeated bimatrix game this approach leads to formation of the game dynamics.

In order to use the specified approach to formation of the solutions to the statistic multi-criteria tasks set above, we'll suppose that the $1^{\text {st }}$ player manages the choice of $u 1$ and $u 2$ component, which purpose is to maximize $F_{1}$ function on $\mathrm{M}$ multitude, and the $2 d$ player choice makes charge of $u 3$ and $u 4$ component, which aim is to maximize $F_{2}$ function on $M$ multitude. At that we'll receive task for development of which solution we use the following algorithm, in which for convenience we mark $u 1=p, u 2=q, u 3=s, u 4=t$.

\subsection{Algorithm}

The solution is searched with assistance of recurrent procedure. May the primary point $(p 0, q 0, s 0, t 0)$ be $\in M$.

Let's describe the algorithm of point $\left(p_{k+1}, q_{k+1}, S_{k+1}, t_{k+1}\right)$ formation $\in M, k=0,1,2, \ldots$

Let's mark

$N_{\varepsilon}\left(p_{k}, q_{k}, s_{k}, t_{k}\right)=\left\{(p, q, s, t) \in M: / p-p_{k} / \leq \varepsilon / 2\right.$,

$\left.\left|q-q_{k}\right| \leq \varepsilon / 2,\left|s-s_{k}\right| \leq \varepsilon / 2,\left|t-t_{k}\right| \leq \varepsilon / 2\right\}$

$N_{\varepsilon}$ multitude is crossing of $\varepsilon$-four-dimensional cube, which centre is in the point $\left(p_{k}, q_{k}, s_{k}, t_{k}\right)$, with $M$ multitude.

Let's set the following tasks:

Task 1. Find $\left(p^{1}, q^{1}, s^{1}, t^{1}\right)$ such as

$\left(p^{1}, q^{1}, s^{1}, t^{1}\right)=\operatorname{argmax} F_{1}(p, q)$

$(p, q, s, t) \in N_{\varepsilon}$

upon condition of

$F_{2}(p, q, s, t) \geq F_{2}\left(p_{k}, q_{k}, s_{k}, t_{k}\right)$

In task 1 the point on $N_{\varepsilon}$ multitude is searched that is the best according to $F_{1}$ indicator upon condition that according to the second indicator it is no worse than the point $\left(p_{k,}, q_{k}, s_{k}, t_{k}\right)$.

Task 2. Find $\left(p^{2}, q^{2}, s^{2}, t^{2}\right)$ such as

$\left(p^{2}, q^{2}, s^{2}, t^{2}\right)=\operatorname{argmax} F_{2}(p, q, s, t)$

$(p, q, s, t) \in N_{\varepsilon}$

upon condition of

$F_{1}(p, q, s, t) \geq F_{1}\left(p_{k}, q_{k}, s_{k}, t_{k}\right)$

Let's develop the additional bimatrix game $(A, B)$ with the following matrixes:

$$
\begin{aligned}
& A=\left(\begin{array}{ll}
\mathrm{F}_{1}\left(\mathrm{p}^{1}, \mathrm{q}^{1}, \mathrm{~s}^{1}, \mathrm{t}^{1}\right) & \mathrm{F}_{1}\left(\mathrm{p}^{1}, \mathrm{q}^{1}, \mathrm{~s}^{2}, \mathrm{t}^{2}\right) \\
\mathrm{F}_{1}\left(\mathrm{p}^{2}, \mathrm{q}^{2}, \mathrm{~s}^{1}, \mathrm{t}^{1}\right) & \mathrm{F}_{1}\left(\mathrm{p}^{2}, \mathrm{q}^{2}, \mathrm{~s}^{2}, \mathrm{t}^{2}\right)
\end{array}\right) \\
& B=\left(\begin{array}{ll}
F_{2}\left(p^{1}, q^{1}, s^{1}, t^{1}\right) & F_{2}\left(p^{1}, q^{1}, s^{2}, t^{2}\right) \\
F_{2}\left(p^{2}, q^{2}, s^{1}, t^{1}\right) & F_{2}\left(p^{2}, q^{2}, s^{2}, t^{2}\right)
\end{array}\right)
\end{aligned}
$$

In this bimatrix game the first strategy of the $1^{\text {st }}$ player lies in the transition from pair $\left(p_{k}, q_{k}\right)$ to pair $\left(p^{1}, q^{1}\right)$, and the second strategy of the $1^{\text {st }}$ player lies in the transition from pair $\left(p_{k}, q_{k}\right)$ to pair $\left(p^{2}, q^{2}\right)$. Similarly the first strategy of the $2 d$ player lies in the transition from pair $\left(s_{k}, t_{k}\right)$ to pair $\left(s^{1}, t^{1}\right)$, and the second strategy of the $2 d$ players lies in the transition from pair $\left(s_{k}, t_{k}\right)$ to pair $\left(s^{2}, t^{2}\right)$. This bimatrix game always has, at least, one Nash's equilibrium in the net strategies.

If this Nash's equilibrium is single one, then it is accepted as $\left(p_{k+1}, q_{k+1}, s_{k+1}, t_{k+1}\right)$, at that it can be either $\left(p^{1}, q^{1}, s^{1}\right.$, $\left.t^{1}\right)$, or $\left(p^{2}, q^{2}, s^{2}, t^{2}\right)$ or $\left(p^{1}, q^{1}, s^{2}, t^{2}\right)$. If there are two Nash's equilibriums (these can be only $\left(p^{1}, q^{1}, s^{1}, t^{1}\right)$ and $\left(p^{2}, q^{2}, s^{2}\right.$, $\left.\left.t^{2}\right)\right)$, then as $\left(p_{k+1}, q_{k+1}, s_{k+1}, t_{k+1}\right)$ either first set, or the second one with equal frequencies is chosen.

As a result after certain quantity of steps we'll receive the final solution (optimal from the point of view of maximization of task criteria).

The previous studies were conducted upon condition that the interest rate of asset allocation (expected profitability), accepted as coverage of the insurance reserves are fixed within the considered period of time.

In the model stated below, the possibility of appearance of some unfavourable situation on the financial market is described, when reduction of the investment income up to full loss of investments as a result of effect of such external 
factor as the sharp change of the expected profits and risks, connected with them make enough strong negative effect on the activity of insurance organization influence. The modern environment of functioning of the different financial institutes, and especially of insurance companies is generally characterized by uncertainty and ambiguity of situations, more specifically aggravated in the process of overcoming of the negative consequences of the world financial crisis and economy destabilization.

So, the necessity of improvement of the model of investment portfolio management of the insurance organization, which take into account the possibility of appearance of such unfavourable situations on the market and allow forming the effective portfolio from the point of view of the most optimal combination of the levels of asset profitability, taken as coverage of insurance reserves and risks connected with it, becomes evident.

\subsection{Multicriteria task of investment portfolio management of insurance organization at availability of dynamic barriers in} the form of changeable interest rates

Formal setting of the task represents the following.

The management vectors $u$ and $v$ have the form of:

$u=\left(u_{1}, u_{2}, u_{3}\right), v=\left(v_{1}, v_{2}, v_{3}\right)$,

where $u_{i}=A_{i}, v_{i}=\Pi_{i}, i=1,2,3, u_{i} \in\left(u_{i}^{*}, u_{i}^{*}\right), v_{i} \in\left(v_{i}^{*}, v_{i}^{*}\right), u \in U, v \in V$.

As the dynamic barriers the interest rates of allocation appear, i.e. the barrier vector

$w=\left(w_{1}, w_{2}, \ldots, w_{5}\right), w \in W$,

We consider that the interest rates $W_{i}$ can change in the set limits, i.e. $W_{i} \in\left(W_{i}^{*}, W_{i}^{*}\right)$, where $W^{*}, W^{*}$ is correspondingly down and upper margin of interest rate change.

Then, having the set of variables:

$\vec{u}=\left(u_{1}, u_{2}\right), \vec{v}=\left(v_{1}, v_{2}\right), \vec{w}=\left(w_{1}, w_{2}, \ldots, w_{5}\right)$,

$u_{1,2}=\grave{e}_{1,2}, v_{1,2}=\grave{e}_{3,4}, w_{i}=P_{p}^{i},(i=\overline{1,5})$,

and singed limitations (3) in accordance with this new set, it is possible to issue the following task:

$\left\{\begin{array}{l}F_{1}(u, v, w) \rightarrow \max \\ F_{2}(u, v, w) \rightarrow \max \\ (u, v) \in M, w \in W\end{array}\right.$

where $M$ multitude represents the merger of multitudes $U$ and $V$.

The method of solution of this task is similar to the method of solution, described in the previous paragraph, but naturally is complicated firstly owing to the increase of quantity and dimension of the space ( $M$ - six-dimensional space), and secondly owing to the availability of dynamic barriers in the form of fluctuating interest rates.

For finding the solution to the task (5), let's issue the additional tasks:

Task 1. Find $\left(u^{1}, v^{1}\right)$, such as $\left(u^{1}, v^{1}\right)=\max \min F_{1}(u, v, w)$

$(u, v) \in M w \in W$

upon condition of $F_{2}^{*}(u, v)>=F_{2}^{*}\left(u^{k}, v^{k}\right)$,

where $F_{2}^{*}(u, v)=\min F_{2}(u, v, w)$

$W \in W$

Task 2.

Find $\left(u^{2}, v^{2}\right)$, such as $\left(u^{2}, v^{2}\right)=\max \min F_{2}(u, v, w)$

$(u, v) \in M w \in W$

upon condition of $F_{1}^{*}(u, v)>=F_{1}^{*}\left(u^{k}, v^{k}\right)$,

where $F_{1}{ }^{*}(u, v)=\min F_{1}(u, v, w)$

$w \in W$

After finding the values of $\left(u^{1}, v^{1}\right)=\left(u_{1}{ }^{1}, u_{2}{ }^{1}, u_{3}{ }^{1}, v_{1}{ }^{1}, v_{2}{ }^{1}, v_{3}{ }^{1}\right)$ and $\left(u^{2}, v^{2}\right)=\left(u_{1}{ }^{2}, u_{2}{ }^{2}, u_{3}{ }^{2}, v_{1}{ }^{2}, v_{2}{ }^{2}, v_{3}{ }^{2}\right)$, the procedure similar to the process of development of the statistical and dynamic task solution stated above is used.

\section{Conclusion}

In conclusion it should be noted that application of the management models offered above allows insures forming the effective investment portfolio and correcting the risk management strategies in such a way that help to achieve the best financial result in the respect of the most optimal combination of the risk and profitability indicators that is especially 
actual in the conditions of destabilization of the financial markets.

\section{References}

Kazak, A.Y., \& Slepukhina, Y.E. (2013). Modern methods of estimation of project risks: traditions and innovations. Bulletin of UrFU: Series Economy and Management, 2, $13-26$.

Slepukhina, Yu.E., \& Kleimenov, A.F. (1998). A multistep multicriteria control problem with uncertainty. In V.D. Batukhtin, F.M. Kirillova, \& V.I. Ukhobotov (Eds.), Proceedings volume from the IFAC Workshop "Nonsmooth and discontinuous problems of control and optimization" (pp. 104-106). Chelyabinsk, Russia, 17-20 June 1998. NY: PERGAMON.

Slepukhina, Y.E. (2006). Financial stability of insurance organizations: theory, models and methods of risk management. Yekaterinburg: Publishing House of USEU.

Slepukhina, Y.E. (2010a). Investment portfolio of insurance organization: financial mechanism of formation and management. Yekaterinburg: Publishing House of AMB.

Slepukhina, Y.E. (2010b). Model of investment portfolio management of insurance organization. University Bulletin (State University of Management), 1, 59-64.

Slepukhina, Y.E. (2010c). The investment portfolio of insurance company: financial mechanism of formation and management. Yekaterinburg: Publishing House of AMB.

Slepukhina, Y.E. (2011). Risk financial management of insurance organization: innovation methods of estimation and analysis. Strakhovoe Delo, 2, 24-32.

Slepukhina, Y.E. (2013). Model of the formation of efficient investment portfolios on financial markets [Online]. International Journal of Applied and Fundamental Research, 2. Available: http://www.science-sd.com/455-24335 (September 2014). 
